Respiration 2013;86:86-87

DOI: $10.1159 / 000348545$

\section{Pharmacological Therapy Does Not Contribute to Survival in Idiopathic Pulmonary Fibrosis}

\author{
Hiroshi Ishii a, b, Hisako Kushima a, b, Kosaku Komiya a, b, \\ Shunji Mizunoe ${ }^{\mathrm{b}}$, Jun-ichi Kadota ${ }^{\mathrm{a}, \mathrm{b}}$ \\ ${ }^{a}$ Department of Respiratory Medicine, Oita University Hospital, \\ Oita, and ${ }^{\mathrm{b}}$ Kyushu Respiratory and Thoracic Study Group, \\ Kyushu, Japan
}

Pirfenidone, 5-methyl-1-phenyl-2-(1H)-pyridone, a compound with anti-inflammatory, antifibrotic and antioxidant properties, has recently been approved in some countries for the treatment of idiopathic pulmonary fibrosis (IPF). In their recent review, Papiris et al. [1] stated that pirfenidone should not be considered as a proven therapy for IPF, because the lack of validated thresholds for the markers used as endpoints in clinical trials has a major impact on the interpretation of the clinical significance of their results, and the highly anticipated data following the approved administration of pirfenidone to IPF patients in Japan in 2008 are still not available. In addition, the scientific community is becoming aware that corticosteroids and immunosuppressants have failed to demonstrate any efficacy in terms of either mortality or in the prevention of acute exacerbations.

We retrospectively assessed the clinical significance of pharmacological therapy, including pirfenidone, especially on the overall survival of patients with IPF. This was a multicenter retrospective study at five hospitals in Kyushu, Japan. The protocol was approved by the respective institutional review boards, but it did not require the patients' approval or informed consent due to the retrospective design of the study. The present study included 183 patients (median age: 69 years), and information was available on the final outcome of the patients, who were treated or untreated between July 1995 and October 2011. All of the subjects were diagnosed clinically to have IPF $(\mathrm{n}=147)$ by chest physicians $(16-21$ years of experience) or histologically to have IPF/usual interstitial pneumonia via a surgical lung biopsy $(n=36)$. Patients who died of complicated lung cancer were excluded from this study.

Among the 183 patients, 85 patients were on medication [prednisolone (PSL) alone $(\mathrm{n}=24)$, PSL + some kind of immunosuppressant $(n=14)$, pirfenidone \pm PSL/immunosuppressant $(n=39)$ and inhaled $\mathrm{N}$-acetyl cysteine \pm PSL/immunosuppressant $(n=8)]$, while the remaining 98 patients were followed without treatment. Some of the patients treated with pirfenidone had participated in phase II or III clinical trials in Japan $[2,3]$. The follow-up lasted a median of 1,553 days (interquartile range: 1-736 days). Although the median age of the patients in the treatment group was lower than that in the untreated group (median: 67 vs. 73 years, $p=$
$0.005)$, there were no significant differences in the median number of deaths ( $46 \mathrm{vs}$. 50) or the duration of the follow-up periods $(1,765$ vs. 1,675 days). A multivariable analysis indicated that acute exacerbation $(n=50,27.3 \%)$ increased the risk for death (hazard ratio $5.1, \mathrm{p}<0.001$ ), and pharmacological therapy did not affect the overall survival in a log-rank test (fig. $1, \mathrm{p}=0.78$ ) after adjusting for other variables, including acute exacerbation. The 5-year survival rate was approximately $40 \%$.

IPF is a fatal lung disease; however, its natural course is variable and unpredictable. Most patients with IPF demonstrate a gradual worsening of lung function over a period of years, while a minority of patients remain stable or decline rapidly [4]. In addition, a differential diagnosis from other interstitial pneumonias, such as idiopathic fibrotic nonspecific interstitial pneumonia, chronic hypersensitivity pneumonitis or the usual interstitial pneumonia pattern of lung-dominant connective tissue diseases, is occasionally difficult in clinical practice. Therefore, the anti-inflammatory effect of pharmacological therapies, including corticosteroids, immunosuppressants and pirfenidone, may improve outcome in a

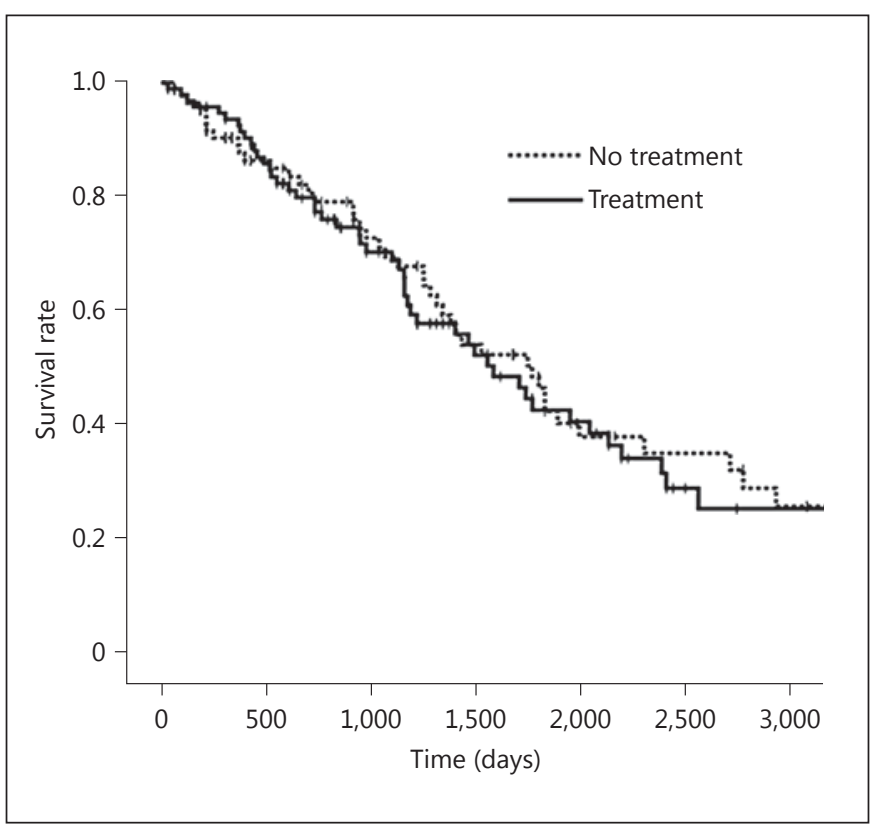

Fig. 1. Kaplan-Meier survival probability based on the presence/ absence of pharmacological therapy in IPF patients. No significant difference was observed in the overall survival between the treatment group $(n=85)$ and the treatment-free group $(n=98, p=$ $0.78)$.

\section{KARGER}

E-Mail karger@karger.com www.karger.com/res
C 2013 S. Karger AG, Basel

0025-7931/13/0861-0086\$38.00/0
Hiroshi Ishii, MD

Department of Respiratory Medicine, Oita University Hospital

1-1 Idaigaoka, Yufu, Oita 879-5593 (Japan)

E-Mail hishii@oita-u.ac.jp 
heterogeneous group of patients with IPF and in patients with diseases mimicking IPF. Although pirfenidone attenuated a range of profibrotic mediators while downregulating histological markers of cellular proliferation in animal models of pulmonary fibrosis [5, $6]$, it should be noted that the concentrations of pirfenidone used in these in vivo experiments were about ten-fold those used in clinical trials.

As suggested by Papiris et al. [1], the most appropriate and clinically meaningful endpoint for assessing drug efficacy in IPF should be overall or progression-free survival, and ideally all-cause mortality and all-cause nonelective hospitalization [7], whereas a minor decline in pulmonary function $[2,3]$ is not thought to be of clinical significance. Although there are currently no validated surrogate endpoints for patients with IPF due to the relatively low prevalence of the disease and the requirement for long-term follow-up in IPF trials, patient-reported outcomes as endpoints are recently coming under reassessment in therapeutic trials of IPF [8].

Nevertheless, the present study has several limitations. This was not a randomized controlled trial, but a small retrospective study. Therefore, the exact results of pulmonary function tests, bronchoalveolar lavage and chest CT findings at the time of the diagnosis or the start of pharmacological treatment were unclear. However, although clinical pirfenidone trials have shown some success in Japan, pharmacological therapies, including pirfenidone, do so far not appear to contribute to the overall survival of IPF patients. Further studies in a larger cohort of patients with true IPF using appropriate endpoints are needed to further evaluate the effects of novel agents.

\section{Acknowledgments}

The authors thank Drs. K. Takahashi (Saga University), N. Sakamoto (Nagasaki University), H. Ishimoto (University of Occupational and Environmental Health, Japan) and N. Matsumoto (Miyazaki University) for participating in the Kyushu Respiratory and Thoracic Study Group (KREST-SG).
Financial Disclosure and Conflict of Interest

The authors have no conflict of interest to declare.

\section{References}

1 Papiris SA, Kagouridis K, Kolilekas L, Triantafillidou C, Tsangaris I, Manali ED: Pirfenidone treatment in idiopathic pulmonary fibrosis: too much of a great expectation? Eur Respir J 2012;40:794-795.

2 Azuma A, Nukiwa T, Tsuboi E, Suga M, Abe S, Nakata K, Taguchi Y, Nagai S, Itoh H, Ohi M, Sato A, Kudoh S: Double-blind, placebo-controlled trial of pirfenidone in patients with idiopathic pulmonary fibrosis. Am J Respir Crit Care Med 2005;171:1040-1047.

3 Taniguchi H, Ebina M, Kondoh Y, Ogura T, Azuma A, Suga M, Taguchi Y, Takahashi H, Nakata K, Sato A, Takeuchi M, Raghu G, Kudoh S, Nukiwa T: Pirfenidone in idiopathic pulmonary fibrosis. Eur Respir J 2010;35:821-829.

4 Raghu G, Collard HR, Egan JJ, Martinez FJ, Behr J, Brown KK, Colby TV, Cordier JF, Flaherty KR, Lasky JA, Lynch DA, Ryu JH, Swigris JJ, Wells AU, Ancochea J, Bouros D, Carvalho C, Costabel U, Ebina M, Hansell DM, Johkoh T, Kim DS, King TE Jr, Kondoh Y, Myers J, Muller NL, Nicholson AG, Richeldi L, Selman M, Dudden RF, Griss BS, Protzko SL, Schunemann HJ, ATS/ERS/JRS/ALAT Committee on Idiopathic Pulmonary Fibrosis: An official ATS/ERS/JRS/ALAT statement: idiopathic pulmonary fibrosis: evidence-based guidelines for diagnosis and management. Am J Respir Crit Care Med 2011;183:788-824.

5 Kakugawa T, Mukae H, Hayashi T, Ishii H, Abe K, Fujii T, Oku H, Miyazaki M, Kadota J, Kohno S: Pirfenidone attenuates expression of HSP47 in murine bleomycin-induced pulmonary fibrosis. Eur Respir J 2004;24:57-65.

6 Oku H, Shimizu T, Kawabata T, Nagira M, Hikita I, Ueyama A, Matsushima S, Torii M, Arimura A: Antifibrotic action of pirfenidone and prednisolone: different effects on pulmonary cytokines and growth factors in bleomycin-induced murine pulmonary fibrosis. Eur J Pharmacol 2008;590:400-408.

7 Raghu G, Collard HR, Anstrom KJ, Flaherty KR, Fleming TR, King TE Jr, Martinez FJ, Brown KK: Idiopathic pulmonary fibrosis: clinically meaningful primary endpoints in phase 3 clinical trials. Am J Respir Crit Care Med 2012;185:1044-1048.

8 Swigris JJ, Fairclough D: Patient-reported outcomes in idiopathic pulmonary fibrosis research. Chest 2012;142:291-297. 